\title{
Appropriateness of healthdirect referrals to the emergency department compared with self-referrals and GP referrals
}

\section{Joseph Y Ng \\ MB BS, FANZCA, Anaesthetist and Registrar in Emergency Medicine \\ Daniel M Fatovich MB BS, FACEM, PhD, Professor of Emergency Medicine ${ }^{1,2,3}$ \\ Valendar F Turner MBBS, FRACS, FACEM Retired Emergency Physician $^{4}$ \\ Jennifer A Wurmel Research Nurse ${ }^{2}$ \\ Sally A Skevington BSW(Hons), Manager $^{5}$ \\ Michael R Phillips BSc(Hons), MMedSc Biostatistician \\ IRoyal Perth Hospital, Perth, WA \\ 2 Centre for Clinical Research in Emergency Medicine Perth, WA. \\ 3 Western Australian Institute for Medical Research University of Western Australia, Perth, WA \\ 4 Perth, WA \\ 5 Strategic System Support Branch, Innovation and Health System \\ Reform Division, Department of Health Perth, WA.}

daniel.fatovich@ health.wa.gov.au

doi: 10.5694/mjal2.10689 MJA 2012; 197: 498-502

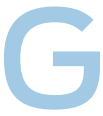

lobally, telephone consultation and triage are increasingly being used to deliver health advice. They have been shown to have high levels of acceptability to callers. $^{1-4}$ A National Health Call Centre Network was established in Australia in 2006, under the auspices of the Council of Australian Governments, as healthdirect Australia. It provides "nationwide access 24 hours a day, seven days a week to healthcare triage, health advice and health information" .5 Calls are answered by registered nurses who use clinical decision support software and their clinical acumen to provide advice and recommended dispositions.

Since inception, healthdirect has referred $2 \%-4 \%$ of callers to an emergency department (ED) via ambulance, and $8 \%-12 \%$ of callers to an ED via private transport (unpublished data, McKesson Asia-Pacific, 20062010). However, the appropriateness of these referrals has not been thoroughly evaluated. In addition, some patients attend the ED after contact with healthdirect even though the advice given is to the contrary. ${ }^{6}$

Our study aimed to characterise the appropriateness and patterns of healthdirect referrals to the $\mathrm{ED}$, and compare these to self-referrals and general practitioner referrals. We hypothesised that contact with healthdirect would result in appropriate referrals to the ED, and that these would be more appropriate than self-referrals.

\section{Methods}

We conducted a prospective observational study at the ED of Royal Perth Hospital. At the time of the study, this adult, tertiary hospital ED had an annual census of about 58000 presentations and a $44 \%$ admission rate. The

Abstract

Objective: To assess the appropriateness of healthdirect referrals to the emergency department (ED) and compare these to self-referrals and general practitioner referrals.

Design and setting: Prospective observational study conducted at the Royal Perth Hospital ED from August 2008 to April 2009, using the healthdirect database to cross check healthdirect advice with ED data.

Patients: Consecutive patients at triage, identified as healthdirect-referred, self-referred or GP-referred (720 patients per group).

Main outcome measure: Appropriateness of referrals, using an a-priori definition.

Results: The healthdirect-referred patients were significantly younger than self-referred and GP-referred patients (mean age, 41.6 years $\vee 45.5$ years and 50.1 years, respectively; $P<0.01)$, more likely to be female $(60.3 \% \vee 43.8 \%$ and $46.4 \%$, respectively; $P<0.01$ ) and more likely to attend the ED out of hours (64.0\% v $45.8 \%$ and $21.0 \%$, respectively; $P<0.01$ ). Self-referred patients had the highest acuity profile $(P<0.01)$. The proportions of referrals that were assessed as being appropriate were: healthdirect-referred, $72.9 \%(95 \% \mathrm{Cl}$, $69.7 \%-76.2 \%$ ); self-referred, $73.8 \%$ (95\% Cl, 70.5\%-77.0\%); and GP-referred, $89.7 \%(95 \% \mathrm{Cl}, 87.5 \%-91.9 \%)$. Of the 534 calls that could be traced back to the healthdirect database, 280 (52.4\%) represented patients who attended the ED despite a contrary recommendation.

Conclusions: GP referrals had the highest level of appropriateness, and healthdirect- and self-referrals had similar levels of appropriateness. More than half the healthdirect-referred patients attended the ED despite a contrary recommendation, probably due to difficulty accessing after-hours health services.

study commenced on 1 August 2008. From this date, consecutive patients were asked the following mandatory question at triage, which uses the Emergency Department Information System (EDIS) system for patient tracking: "Were you referred by healthdirect today?" The first 720 of those who answered "yes" were classified as healthdirect-referred patients. From the same date, 720 consecutive self-referred and 720 GP-referred patients were identified by information obtained at triage. Approval for the study was given by the Royal Perth Hospital Human Research Ethics Committee. Existing data-sharing arrangements between the Department of Health, Western Australia, and McKesson Asia-Pacific were observed. (McKesson Asia-Pacific delivered healthdirect under contract to the National Health Call Centre Network at the time of the study).

\section{Calls to healthdirect}

From July 2008 to June 2009, 573160 calls were answered by healthdirect. ${ }^{7}$ About $70 \%$ of calls were from people who had symptoms they were concerned about and who wanted to speak to a nurse. Other calls were for health information, service locations and other queries. ${ }^{7}$ Recommended dispositions provided to callers, which were based purely on symptoms, included

- emergency dispositions of immediate attendance at an ED, by ambulance dispatched through St John Ambulance (via Triple Zero [000]) or by own transport 
- acute dispositions recommending expedited attendance at a general practice (immediately, within $4 \mathrm{~h}$ or within $24 \mathrm{~h}$ )

- non-acute dispositions such as routine attendance at a general practice (within $72 \mathrm{~h}$ or within 2 weeks), self-care with advice provided, or other services.

\section{Data collection}

The data were obtained by reviewing the following systems for all patients: EDIS, iSOFT Clinical Manager 1.4 (iSOFT Group), and IMPAX (a picture archiving and communication system) (Agfa-Gevaert Group). Manual medical record review was performed whenever electronic data were incomplete. For patients referred by healthdirect, the healthdirect database - CareEnhance Call Centre (CeCC) software (McKesson Corporation) - was interrogated at McKesson, using demographic data provided by patients at triage. This enabled crosschecking of referral advice with ED data. Data were collected prospectively by one of us (JAW), using a preformatted data abstraction form. Out of hours was defined as outside the hours of 08:00-18:00. The data were verified by one of us (JYN).

\section{Primary outcome}

The primary outcome of the study was appropriateness of referrals, which we defined a priori as one or more of

- admission to hospital

- referral to an inpatient team for assessment

- referral to an outpatient clinic

- transfer to another hospital

- death in the ED

- performance of any radiological or laboratory investigations.
In the absence of these events, it was assumed that the patient could have been adequately assessed and treated in a non-ED setting (ie, the referral was considered not appropriate).

\section{Statistical analysis}

The power calculation was based on the assumptions that the ratio of healthdirect referrals to self-referrals is about $1: 40$, the ratio of healthdirect referrals to GP referrals is about $1: 5$, and that $50 \%$ of self-referrals and $80 \%$ of GP referrals are appropriate according to our definition. With a sample of 720 patients in each group, this study had $>90 \%$ power to detect as statistically significant $(P<0.05)$ a $12 \%$ difference in appropriateness between healthdirect- and self-referred patients, and a $7 \%$ difference between healthdirect- and GP-referred patients. The study was also powered for subset analysis of differences between healthdirect-referred patients who were able to be traced back to the healthdirect database versus those who were not, and a subset analysis of ambulance use across the three patient groups.

Statistical testing was performed on PASW Statistics 18.0 (SPSS). Categorical data were analysed using the Pearson $\chi^{2}$ test, with the Fisher exact test substituted for $2 \times 2$ comparisons with small numbers. Numerical data were analysed using Kruskal-Wallis one-way analysis of variance.

\section{Results}

We enrolled 720 patients per group. The healthdirect-referred patients were identified by 16 April 2009, self- referred patients were identified by 7 August 2008, and GP-referred patients were identified by 8 October 2008. During the study period, there was a total of 42060 attendances to the Royal Perth Hospital ED, of which 720 were healthdirect-referred patients, 33244 self-referred patients and 3814 GP-referred patients; this represented $1.7 \%, 79.0 \%$ and $9.1 \%$ of the attendances, respectively (4282 attendances [10.2\%] were from other sources). Hence, the ratio of healthdirect referrals to self-referrals was $1: 46$ and the ratio of healthdirect referrals to GP referrals was $1: 5$.

The demographic and presentation characteristics of each patient group are reported in Box 1. The healthdirectreferred patients were significantly younger than patients in the other groups $(P<0.01)$, more likely to be female $(P<0.01)$ and more likely to attend the ED out of hours $(P<0.01)$. Self-referred patients had the highest acuity profile on the Australasian Triage Scale $(P<0.01)$. GP-referred patients and healthdirect-referred patients did not significantly differ in their acuity $(P=0.52)$. Length of stay was significantly shorter for healthdirect-referred patients $(P<0.01)$.

The top 10 diagnostic categories for each group are shown in Box 2. Overall, injury was the most frequent presenting complaint. Toxicological and psychiatric presentations were more frequent among self-referred patients.

Of the 720 healthdirect-referred patients, $186(25.8 \%)$ could not be traced back to the healthdirect database. Possible reasons include incomplete demographic data, anonymous

1 Demographic and presentation characteristics of the three patient groups ( $n=720$ per group)*

\begin{tabular}{|c|c|c|c|}
\hline & healthdirect-referred patients & Self-referred patients & General practitioner-referred patients \\
\hline Mean (95\% Cl; SD) age, years ${ }^{\dagger}$ & $41.6(40.2-43.0 ; 18.8)$ & $45.5(43.9-47.1 ; 21.3)$ & $50.1(49.2-52.3 ; 21.3)$ \\
\hline Female & $434(60.3 \%[56.7 \%-63.9 \%])$ & 315 (43.8\% [40.1\%-47.4\%]) & $334(46.4 \%$ [42.7\%-50.0\%]) \\
\hline Aboriginal or Torres Strait Islander & $15(2.1 \%[1.0 \%-3.1 \%])$ & $47(6.5 \%[4.7 \%-8.3 \%])$ & $26(3.6 \%[2.2 \%-5.0 \%])$ \\
\hline Attended ED out of hours & 461 (64.0\% [60.5\%-67.5\%]) & $330(45.8 \%$ [42.2\%-49.5\%]) & $151(21.0 \%$ [18.0\%-24.0\%]) \\
\hline Australasian Triage Scale 1 & $4(0.6 \%)$ & $21(2.9 \%)$ & $1(0.1 \%)$ \\
\hline Australasian Triage Scale 2 & $130(18.1 \%)$ & $163(22.6 \%)$ & $140(19.4 \%)$ \\
\hline Australasian Triage Scale 3 & $264(36.7 \%)$ & $206(28.6 \%)$ & $278(38.6 \%)$ \\
\hline Australasian Triage Scale 4 & $286(39.7 \%)$ & $279(38.8 \%)$ & $267(37.1 \%)$ \\
\hline Australasian Triage Scale 5 & $36(5.0 \%)$ & $51(7.1 \%)$ & $34(4.7 \%)$ \\
\hline Ambulance use & $97(13.5 \%[11.0 \%-16.0 \%])$ & 262 (36.4\% [32.9\%-39.9\%]) & 124 (17.2\% [14.5\%-20.0\%]) \\
\hline Median (IQR) length of stay in ED, h:min & $3: 50(2: 09-6: 28)$ & $4: 15(2: 33-7: 37)$ & $5: 19(3: 18-8: 41)$ \\
\hline
\end{tabular}


2 Top 10 diagnostic categories for the three patient groups ( $n=720$ per group) based on International Classification of Diseases (10th revision) codes, classified into organ systems

healthdirect-referred patients

\begin{tabular}{|c|c|c|c|c|c|}
\hline Diagnostic category & No. (\%) & Diagnostic category & No. (\%) & Diagnostic category & No. (\%) \\
\hline Gastrointestinal & $118(16.4 \%)$ & Injury (external) & $130(18.1 \%)$ & Gastrointestinal & $105(14.6 \%)$ \\
\hline Injury (external) & $77(10.7 \%)$ & Cardiovascular & $83(11.5 \%)$ & Cardiovascular & $89(12.4 \%)$ \\
\hline Cardiovascular & $74(10.3 \%)$ & Gastrointestinal & $70(9.7 \%)$ & Injury (orthopaedic) & $74(10.3 \%)$ \\
\hline Did not wait & $60(8.3 \%)$ & Did not wait & $65(9.0 \%)$ & Injury (external) & $66(9.2 \%)$ \\
\hline Genitourinary & $50(6.9 \%)$ & Injury (orthopaedic) & $63(8.8 \%)$ & Neurological & $55(7.6 \%)$ \\
\hline Neurological & $49(6.8 \%)$ & Neurological & $43(6.0 \%)$ & Respiratory & $51(7.1 \%)$ \\
\hline Respiratory & $40(5.6 \%)$ & Respiratory & $42(5.8 \%)$ & Ophthalmological & $45(6.3 \%)$ \\
\hline Ear, nose and throat & $38(5.3 \%)$ & Genitourinary & $38(5.3 \%)$ & Genitourinary & $36(5.0 \%)$ \\
\hline Injury (orthopaedic) & $34(4.7 \%)$ & Toxicological and poisoning & $27(3.8 \%)$ & Dermatological & $36(5.0 \%)$ \\
\hline Dermatological & $29(4.0 \%)$ & Psychiatric & 26 (3.6\%) & Haematological & $32(4.4 \%)$ \\
\hline
\end{tabular}

\section{Appropriateness of referrals for the three patient groups ( $n=720$ per group)}

\begin{tabular}{|c|c|c|c|}
\hline & \multicolumn{3}{|c|}{ Number $(\%, 95 \% \mathrm{Cl})$} \\
\hline & healthdirect-referred patients & Self-referred patients & General practitioner-referred patients \\
\hline Appropriate & 525 (72.9\%, 69.7\%-76.2\%) & 531 (73.8\%, 70.5\%-77.0\%) & 646 (89.7\%, 87.5\%-91.9\%) \\
\hline Admitted to hospital & 185 (25.7\%, 22.5\%-28.9\%) & 257 (35.7\%, 32.2\%-39.2\%) & 335 (46.5\%, 42.9\%-50.2\%) \\
\hline Referred to inpatient team & 239 (33.2\%, 29.7\%-36.6\%) & 317 (44.0\%, 40.4\%-47.7\%) & $467(64.9 \%, 61.4 \%-68.4 \%)$ \\
\hline Referred to outpatient clinic & $34(4.7 \%, 3.2 \%-6.3 \%)$ & 71 (9.9\%, 7.7\%-12.0\%) & $137(19.0 \%, 16.2 \%-21.9 \%)$ \\
\hline Transferred to another hospital & 11 (1.5\%, 0.6\%-2.4\%) & $13(1.8 \%, 0.8 \%-2.8 \%)$ & $9(1.3 \%, 0.4 \%-2.1 \%)$ \\
\hline Death in emergency department & $0(0,0-0.6 \%)$ & $3(0.4 \%, 0.1 \%-1.3 \%) *$ & $0(0,0-0.6 \%)$ \\
\hline Laboratory investigation & 439 (61.0\%, 57.4\%-64.5\%) & 396 (55.0\%, 51.4\%-58.6\%) & 504 (70.0\%, 66.6\%-73.4\%) \\
\hline Radiological investigation & 302 (41.9\%, 38.3\%-45.6\%) & 366 (50.8\%, 47.2\%-54.5\%) & $442(61.4 \%, 57.8 \%-65.0 \%)$ \\
\hline
\end{tabular}

callers, and patients who reported contacting healthdirect but actually did not. However, there were no significant differences in demographic and presentation characteristics between traceable and non-traceable patients.

\section{Appropriateness of referrals}

Appropriateness of the referrals in each patient group, according to our a-priori definition, is shown in Box 3 . It was highest for GP-referred patients - significantly higher than in the other groups $(P<0.01)$. Appropriateness was similar in healthdirectreferred and self-referred patients $(P=$ $0.72)$. Self-referred patients were more likely than healthdirect-referred patients to be admitted to hospital $(P<0.01)$, referred to an inpatient team $(P<0.01)$, referred to an outpatient clinic $(P<0.01)$ or have a radiological investigation $(P<0.01)$. The only deaths in the study were in the self-referred group.

For the 534 calls that could be traced back to the healthdirect database, the median call-to-triage time was $1 \mathrm{~h} 51 \mathrm{~min}$ (interquartile range,
$1 \mathrm{~h} 9 \mathrm{~min}$ to $2 \mathrm{~h} 35 \mathrm{~min}$ ). The appropriateness of these referrals, according to the recommended disposition, is shown in Box 4. Only 254 patients $(47.6 \%)$ were recommended to attend the ED. A further 254 patients $(47.6 \%)$ attended the ED after being recommended to see a GP in an expedited fashion (immediately, within $4 \mathrm{~h}$ or within $24 \mathrm{~h}$ ) and 26 patients $(4.9 \%)$ were referred for non-acute care such as seeing a GP within 2 weeks or were given self-care advice.

\section{Recommendations to attend, or not attend, the ED}

A comparison of patients recommended to attend the ED versus those recommended to not attend the ED showed no significant differences in age, sex, ethnicity or out-of-hours presentation. Based on our a-priori definition, appropriateness of these referrals was not significantly different between the two groups (77.6\% [197/ 254; $95 \%$ CI, $72.4 \%-82.7 \%$ ] v $70.4 \%$ [197/280; 95\% CI, 65.0\%-75.7\%]; $P=$ $0.06)$. However, those who were recommended to attend the ED were significantly more likely to be admitted to hospital $(30.7 \%$ [78/254; $95 \%$ CI, $25.0 \%-36.4 \%]$ v $17.5 \%$ [49/280; $95 \% \mathrm{CI}, 13.0 \%-22.0 \%] ; P<0.01)$, to be referred to an to inpatient team (39.8\% [101/254; $95 \%$ CI, $33.7 \%-$ $45.8 \%]$ v $24.6 \%$ [69/280; 95\% CI, $19.6 \%-29.7 \%] ; P<0.01)$, to have laboratory investigations $(67.7 \% \quad[172 /$ 254; $95 \%$ CI, $61.9 \%-73.5 \%$ ] $55.7 \%$ [156/280; 95\% CI, $49.9 \%-61.6 \%]$; $P<0.01$ ), and to have radiological investigations (48.0\% [122/254; 95\% CI, $41.9 \%-54.2 \%]$ v $34.3 \%$ [96/280; 95\% CI, 28.7\%-39.9\%]; P<0.01).

\section{Appropriateness of ambulance use}

Ambulance use in each patient group is shown in Box 5. In our study population, $22.4 \%$ of patients (483/2160) used an ambulance as their mode of transport to the ED. Using our a-priori definition of referral appropriateness as a proxy for appropriate ambulance use, ambulance use was appropriate for $87.4 \%$ of ambulance users (422/483; 95\% CI, 84.4\%-90.3\%), compared with $76.3 \%$ of non-ambulance users (1280/ 1677; 95\% CI, 74.3\%-78.4\%) $(P<0.01)$. 
4 Appropriateness of referrals by healthdirect disposition category for traceable calls

\begin{tabular}{lcc} 
Disposition & $\begin{array}{c}\text { Traceable calls, number/ } \\
\text { denominator (\%) }\end{array}$ & $\begin{array}{c}\text { Appropriate referrals, number/ } \\
\text { denominator }(\%, 95 \% \mathrm{CI})\end{array}$ \\
\hline Emergency & $254 / 534(47.6 \%)$ & $198 / 254(78.0 \%, 72.2 \%-82.8 \%)$ \\
Acute & $254 / 534(47.6 \%)$ & $181 / 254(71.3 \%, 65.2 \%-76.7 \%)$ \\
Non-acute & $26 / 534(4.9 \%)$ & $15 / 26(57.7 \%, 37.2 \%-76.0 \%)$
\end{tabular}

A higher proportion of ambulance use by GP-referred patients $(95.2 \%$ [118/124]; 95\% CI, 91.3\%-99.0\%) was appropriate - significantly more than for self-referred patients $(82.8 \%$ [217/ 262; 95\% CI, 78.2\%-87.4\%]; $P<0.01$ ) but not significantly more than for healthdirect-referred patients $(89.7 \%$ [87/97; 95\% CI, 83.5\%-95.9\%]; P= 0.12). However, of the healthdirectreferred patient group, call tracing revealed that 32 of 33 ambulance trips directly initiated by healthdirect triage nurses $(97.0 \%)$ were appropriate.

\section{Discussion}

We found that the appropriateness of healthdirect referrals to the ED was similar to that of self-referrals and lower than that of GP referrals. GPreferred patients were older, had the highest level of appropriate ambulance use and the highest admission rate, reflecting appropriate referral patterns and perhaps a different casemix.

Our results highlight that patients are very good at working out that they are seriously ill and require ED services. The self-referred patient group had the highest acuity profile and the only deaths. However, some patients may be less certain of their need for emergency care and call healthdirect to confirm their own assessment of their situation. $^{8,9}$

One can argue that the healthdirectreferred patients in this study had low rates of compliance, as the recommended disposition for half was to use non-ED services or self-care. We believe that this relates principally to the limited availability of after-hours health services as our data show a prominence of out-of-hours attendances in the healthdirect-referred group, especially when compared with the GP-referred group. However, it may also reflect an inherent fallibility of the telephone consultation model. In any case, patients will interpret the advice they are given in the context of their own perceptions. It would be interesting to survey such patients to more accurately define barriers to compliance.

There has been considerable discussion and debate regarding the value of telephone advice services within the health system. ${ }^{9}$ Often, the impetus given for such services is to reduce demand for ED services. ${ }^{9}$ However, this is a misplaced argument. The lay public want and need access to health information and advice, and very high satisfaction with telephone advice services has been reported. ${ }^{4,7,10,11}$ To justify the cost of providing such a service, reducing demand for ED services is often promoted, but this just perpetuates the myth that EDs are overrun with patients who could more appropriately receive care in a general practice setting. ${ }^{9}$ This is a simplistic explanation of the complex issue of ED overcrowding. ${ }^{9,12}$

To date, it has been shown that telephone triage services have limited capacity to influence ED use or workload. ${ }^{6}$ A Cochrane review found that no study has shown a decrease in ED attendances and one study has found that nurse telephone consultation increased ED attendances. ${ }^{13}$ Given that healthdirect referrals to the ED in our study represented fewer than $2 \%$ of ED attendances, the impact of telephone triage is minimal, consistent with the results of the Cochrane review. Also, there have been no costeffectiveness studies on telephone triage services, and such services used to be provided by EDs. ${ }^{14}$ The finding that more than half the healthdirectreferred patients in our study attended the ED despite a contrary recommendation spotlights the issue of access to after-hours health services. Also, healthdirect's nurse-led telephone triage service was extended in July 2011 by adding GP support, as the after-hours GP helpline. ${ }^{15}$ It would be interesting to see whether this has affected the appropriateness of healthdirect referrals.

A limitation of our study is that the definition of appropriateness that we used is imperfect. It did, however, enable us to use electronic methods of assessing appropriateness using objective data. There is no gold standard definition of appropriateness. Factors that may influence appropriateness include the social aspects of illness that are not captured by electronic systems. Also, the performance of laboratory and radiological testing may not necessarily reflect a high degree of urgency. Another limitation is that some patients would have been unable to answer the mandatory question at triage (eg, they may have been unconscious or may not have understood the question). In addition, as an adult tertiary referral ED, our results may have limited external generalisability, especially because telephone advice for paediatric patients usually forms the major component of telephone triage services. Finally, there may have been some seasonal variation in illnesses that affected our results.

In summary, we found that GP referrals to our ED had the highest level of appropriateness. The healthdirect-referrals and self-referrals had similar levels of appropriateness. ED attendance despite contrary recom-

5 Ambulance use of the three groups ( $n=720$ per group)

\begin{tabular}{lccc} 
& \multicolumn{3}{c}{ Number (\%, 95\% CI) } \\
\cline { 2 - 4 } & $\begin{array}{c}\text { healthdirect-referred } \\
\text { patients }\end{array}$ & $\begin{array}{c}\text { Self-referred } \\
\text { patients }\end{array}$ & $\begin{array}{c}\text { General practitioner-referred } \\
\text { patients }\end{array}$ \\
\hline Ambulance used & $97(13.5 \%, 11.0 \%-16.0 \%)$ & $262(36.4 \%, 32.9 \%-39.9 \%)$ & $124(17.2 \%, 14.5 \%-20.0 \%)$ \\
Ambulance used and appropriate & $87(89.7 \%, 83.5 \%-95.9 \%)$ & $217(82.8 \%, 78.2 \%-87.4 \%)$ & $118(95.2 \%, 91.3 \%-99.0 \%)$
\end{tabular}


mendations is likely to reflect the difficulty accessing after-hours health services.

\section{Acknowledgements: This study was funded by the Department of Health, Western Australia.}

Competing interests: Joseph $\mathrm{Ng}$ is a former paid adviser to McKesson Asia-Pacific. Valendar Turner was a paid employee of the Project Development Division, Department of Health, Western Australia, from 1999 to 2009. Sally Skevington is a paid employee of the Innovation and Health System Reform Division, Department of Health, Western Australia.

Received 23 Apr 2012, accepted 25 Sep 2012

1 Barber JW, King WD, Monroe KW, Nichols MH. Evaluation of emergency department referrals by telephone triage. Pediatrics 2000; 105: 819-821.

2 Munro J, Nicholl J, O'Cathain A, Knowles E. Impact of NHS direct on demand for immediate care: observational study. BMJ 2000; 321: 150-153.

3 St George IM, Cullen MJ. The Healthline pilot: call centre triage in New Zealand. N Z Med J 2001; 114: 429-430.
4 Turner VF, Bentley PJ, Hodgson SA, et al. Telephone triage in Western Australia. Med J Aust 2002; 176: 100-103.

5 healthdirect Australia. Health information services. http://www.healthdirect.org.au (accessed Oct 2012).

6 Sprivulis P, Carey M, Rouse I. Compliance with advice and appropriateness of emergency presentation following contact with the healthdirect telephone triage service. Emerg Med Australas 2004; 16: 35-40.

7 National Health Call Centre Network. healthdirect Australia report card, July 2008 June 2009. http://www.healthdirect.org.au/ download.cfm?downloadfile=470CDE40-7F6EIIDF-968300155D285803 (accessed Oct 2012).

8 Ström M, Marklund B, Hildingh C. Callers' perceptions of receiving advice via a medical care help line. Scand J Caring Sci 2009; 23: 682-690.

9 Nagree $Y$, Cameron P, Gosbell A, Mountain D. Telephone triage is not the answer to ED overcrowding. Emerg Med Australas 2012; 24 123-126.

10 Fatovich DM, Jacobs IG, McCance JP, et al. Emergency department telephone advice. Med J Aust 1998; 169: 143-146.
11 National Health Call Centre Network. healthdirect Australia: annual survey report, August 2010. http://www.healthdirect.org.au/ download.cfm?downloadfile=F41910AC-B587IIDF-A5C40050568619B2 (accessed Oct 2012)

12 Richardson DB, Mountain D. Myths versus facts in emergency department overcrowding and hospital access block. Med J Aust 2009; 190: 369-374.

13 Bunn F, Byrne G, Kendall S. Telephone consultation and triage: effects on health care use and patient satisfaction. Cochrane Database Syst Rev 2004; (4): CD004180.

14 Fatovich D, Jacobs I. Emergency department telephone advice: a survey of Australian emergency departments. Emerg Med Australas 1998; 10: 117-121. doi: 10.1111/j.1442-2026.1998. tb00668.x.

15 Roxon N. It's 3 am and your GP is closed - who can you call [media release]? 2 Jun 2011. http:// www.health.gov.au/internet/ministers/ publishing.nsf/Content/00380EC30FABAICDC A2578A300069A66/\$File/nrl12.pdf (accessed Oct 2012).

\section{Stamps of greatness}

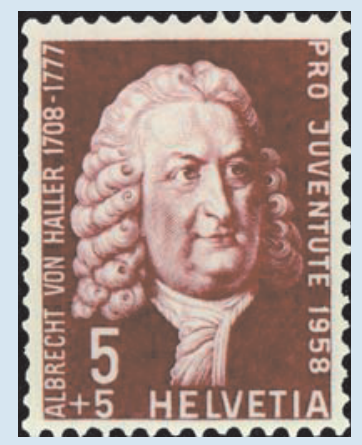

\section{Albrecht von Haller (1708-1777)}

HALLER, one of the greatest

physiologists of the 18th century and the leader of the Systematist School, was born in Berne, Switzerland, on 16 October 1708

He belonged to the old bourgeois aristocracy of Berne but was orphaned at an early age.

Nevertheless he received a

thorough, basic education in the humanities from his uncle,

Dr Neuhaus of Biel.

Haller was an infant prodigy, writing Latin verses and a Chaldee grammar at the age of 10 years, and disproving Professor Georg Coschwitz's contention that the lingual vein was a salivary duct at age 16 .

He started his medical studies at the University of Tubingen, aged 15, and continued them later at Leyden, having men like Boerhaave, Albinus, Winslow and Bernoulli as teachers. He graduated in 1729 at the age of 19 years.

In 1736 he was appointed professor of physiology at the new University of Gottingen, where he remained for 17 years, teaching all branches of medicine, establishing a botanic garden and churches, writing some 13000 scientific papers and doing his best experimental work.

Haller returned to Berne in 1753 to spend the rest of his days in various activities as public health officer, a member of the Swiss Council, an economist, the founder of a philological seminary and a state orphan asylum, and the head of his canton. He was knighted in 1749 by the Empress Marie-Theresa of
Austria and also knighted and made a Fellow of the Royal Society by George II of Great Britain.

Haller was equally eminent as an anatomist, a physiologist, a botanist and a mathematician. He wrote poetry and historical novels and carried on perhaps the most prolific correspondence in the history of science. He was the principal founder of medical and scientific bibliographies. He did a lot of work in the anatomical illustration of blood vessels and the viscera and on the physiology of muscle contractility and irritability. He recognised the role of bile in the digestion of fats (1736) and was the first to inject putrid material into the living body (1760). However, he was something of a reactionary in embryology and opposed Caspar Wolff's - correct - views on the topic.

Haller lectured and wrote on surgery yet never performed an actual operation during his career. He described a fusiform aneurysm of the aortic arch, the corpus luteum and a very early fetus. He also wrote a history of medicine in 1751.

In 1746 he wrote on the mechanism of breathing and recorded the role of the intercostal muscles in respiration. He even appears in the memoirs of Casanova, who was struck by his profound knowledge and exquisite courtesy.

In private life he was modest and charitable, and would affirm his ignorance when he could not explain a phenomenon. But he was complacent as to his infallibility about what he professed to know, did not like to have it questioned and so left no school of followers.

Haller died in Berne on 12 December 1777, and was postally honoured by Switzerland in 1934 and again in 1958 as a great physician. 